\title{
Flow and turbulence in vegetation in a channel
}

\begin{abstract}
The distribution of aquatic vegetation within conveyance channels plays a key role in the determination of their hydraulic characteristics, especially where the vegetation is patchy, as is commonly found in nature. This paper reports the results of a laboratory flume study on flow and turbulence conditions caused by patches of the emergent rush Lepironia articulata. Acoustic Doppler velocimeter measurements were taken within and downstream of singleand multiple-patch configurations of this plant, and the effects of varying incident flow rate $(0 \cdot 16 \mathrm{i} 0.32 \mathrm{~m} / \mathrm{s})$ and stem-scale porosity (12ï $4 \%$ solid volume fraction) were investigated. The results showed that flow encountering a single patch formed a turbulent wake downstream of the vegetation. Within this wake, the Reynolds stress increased downstream initially, and then decayed. When a second patch was positioned within the region of maximum Reynolds stress, the Reynolds stress decreased by between 25 and $50 \%$. The amount of this reduction was dependent on the porosity of the vegetation and the flow rate, and was greater at lower flow rates and porosities. These changes in turbulent flow fields around patches of emergent vegetation are likely to be important in determining sediment budgets in their vicinity.
\end{abstract}

Keyword: Environment; Hydraulics \& hydrodynamics; Waterways \& canals 